\title{
Sound Source Localisation for a High-Speed Train and Its Transfer Path to Interior Noise
}

\author{
Jie Zhang ${ }^{*} \mathbb{0}$, Xinbiao Xiao, Xiaozhen Sheng and Zhihui Li
}

\begin{abstract}
Noise is one of the key issues in the operation of high-speed railways, with sound source localisation and its transfer path as the two major aspects. This study investigates both the exterior and interior sound source distribution of a high-speed train and presents a method for performing the contribution analysis of airborne sound with regard to the interior noise. First, both exterior and interior sound source locations of the high-speed train are identified through in-situ measurements. Second, the sound source contribution for different regions of the train and the relationships between the exterior and interior noises are analysed. Third, a method for conducting the contribution analysis of airborne sound with regard to the interior noise of the high-speed train is described. Lastly, a case study on the sidewall area is carried out, and the contribution of airborne sound to the interior noise of this area is obtained. The results show that, when the high-speed train runs at $310 \mathrm{~km} / \mathrm{h}$, dominant exterior sound sources are located in the bogie and pantograph regions, while main interior sound sources are located at the sidewall and roof. The interior noise, the bogie area noise and the sound source at the middle of the coach exhibit very similar rates of increase with increasing train speed. For the selected sidewall area, structure-borne sound dominates in most of the 1/3 octave bands.
\end{abstract}

Keywords: High-speed train, Interior noise, Sound transfer path, Noise source identification, Exterior noise, Airborne sound

\section{Introduction}

In recent years, China's high-speed railway has developed rapidly. A series of new high-speed lines and high-speed trains have been built. Therefore, new challenges have emerged, necessitating further research. Noise is one of the key issues for operating high-speed railways [1-5], with sound source localisation and its transfer path as the two main aspects.

The major noise sources for a high-speed train are wheel/rail rolling noise and pantograph aerodynamic noise [6, 7]. Remington [8] and Thompson [9] conducted comprehensive research on mechanism of generation and ways to predict the wheel/rail noise. Wu et al. [10] studied the rolling noise generated by wheel/track parametric excitation. They found that the use of the moving irregularity model without considering wheel/track parametric excitation may lead to underestimation of the noise level

${ }^{*}$ Correspondence: zh.receive@gmail.com

State Key Laboratory of Traction Power, Southwest Jiaotong University, Chengdu 610031, China at high speeds. Sheng et al. [11] extended the Fouriertransform-based method to obtain revised equations that are appropriate for predicting sound radiation from slab high-speed railway tracks. Zhang et al. [12] investigated the effects of ballast on sound radiation from the railway track, with the conclusion that ballast vibration can increase the sound radiation by $1-4.5 \mathrm{~dB}$ for frequencies between $20 \mathrm{~Hz}$ and $300 \mathrm{~Hz}$ at the full scale, whereas at higher frequencies the effect is negligible. Nagakura [13] performed wind tunnel tests using a 1/5 scale Shinkansen train model and analysed the distribution of aerodynamic noise sources. Latorre Iglesias et al. [14] proposed a semiempirical component-based model to predict the aerodynamic noise from train pantographs.

Eliminating noise sources is the most direct and effective method of noise control. Therefore, it is important to study the sources and the associated mechanisms of noise generation. Furthermore, studying sound source localisation and its transfer path is also important, because these two aspects directly influence noise control measures. Mellet et al. [15] investigated the contribution 
of the aerodynamic/rolling noise for high-speed trains. They concluded that whether or not the rolling noise is the most important source, it depends on not only the train speed but also the wheel/rail surface conditions. Zea et al. [16] introduced a wavenumber-domain filtering technique, referred to as wave signature extraction, to separate the rail contribution to the total pass-by noise. The advantage of the method is that, in principle, no prior knowledge of the structural properties of the track is needed. Ström [17] used the operational transfer path analysis technique to compare transmission of the outside noise to the interior noise by different paths within a high-speed train bogie. It is found that the three important paths in the frequency range analysed are the airborne transfer path, traction rod and yaw dampers. Fan et al. [18] used the sound intensity and partial coherence methods to identify the most significant sources of the interior noise. They found that the major source of the interior noise is the structural-borne sound radiated by floor vibration. Zhang et al. [19] presented a detailed statistical energy analysis and contribution analysis for the interior noise of a high-speed train. They found that for the studied coach the key factors determining the interior noise are the sidewall vibration, bogie area noise, and floor acoustic transmission loss.

In summary, it is obvious that there are many researches on sound sources and noise transfer paths. However, for high-speed trains, there is still a lack of joint analysis of interior sources and exterior sources, especially the quantitative analysis of the transfer contribution from the exterior to the interior, which is precisely the key to control the interior noise. This study investigates both exterior and interior sound source distributions of a high-speed train and presents a method for contribution analysis of airborne sound to the interior noise. In Section 2, both exterior and interior sound source locations of a high-speed train are identified through in-situ measurements. The sound source contributions of different regions and relationships between the exterior and interior noises are analysed. In Section 3, a method for the contribution analysis of airborne sound to the interior noise of the high-speed train is described. In Section 4, a case study for the sidewall area is then carried out, and the contribution of airborne sound to the interior noise of that area is obtained. Finally, the conclusions are provided in Section 5.

\section{Exterior and Interior Sound Source Localisations}

The measured high-speed train consists of eight coaches. The first, the third, the sixth and the last coaches are trailer car, while the other coaches are motor car. The length, the width and the height (from rail head and not include the pantograph) of the train are, respectively,
$209 \mathrm{~m}, 3.36 \mathrm{~m}$ and $4.05 \mathrm{~m}$. There is slab track on the viaduct using UIC 60 rail and WJ-8A fastening. The sidewall height is about $0.68 \mathrm{~m}$ relative to the bridge deck.

\subsection{Distribution of Exterior Sound Sources}

Figure 1 shows a test photograph of the measurement of the exterior noise source of a high-speed train running at $310 \mathrm{~km} / \mathrm{h}$, conducted using a 78-channel wheel microphone array (B\&K WA-0890-F). The diameter of the array is $4 \mathrm{~m}$, and the array centre was $7.5 \mathrm{~m}$ away from the centreline of the track and $2 \mathrm{~m}$ above the rail surface.

The software B\&K NSI array acoustics post-processing was used for the exterior noise source identification analysis. The focus points are all set to be in the plane of the sidewall which is $5.8 \mathrm{~m}$ from the microphone array. The method is called rail vehicle moving source beamforming (BZ-5939) [20-22]. Figure 2 illustrates the distribution of the exterior noise sources of the train running at $310 \mathrm{~km} / \mathrm{h}$.

It can be seen from Figure 2 that the main exterior noise sources of the high-speed train running at $310 \mathrm{~km} / \mathrm{h}$ are located at the bogie area and pantograph area. The noise generated from the bogie area includes the wheel/rail rolling noise, gear noise, and bogie aerodynamic noise. It can be seen that the sound intensity levels of different bogies are quite different. The noise levels decrease from the first to the last bogie. Because the rolling noise and gear noise are approximately equal for each bogie, the main cause of the bogie noise difference is the bogie aerodynamic noise $[23,24]$. The aerodynamic noise plays an important role, especially in the first five bogies, when the train is running at a high speed such as $310 \mathrm{~km} / \mathrm{h}$.

The side surface of the high-speed train is divided into eight areas, as shown in Figure 3, which are the bogie area, pantograph area, head area, rear area, inter-coach

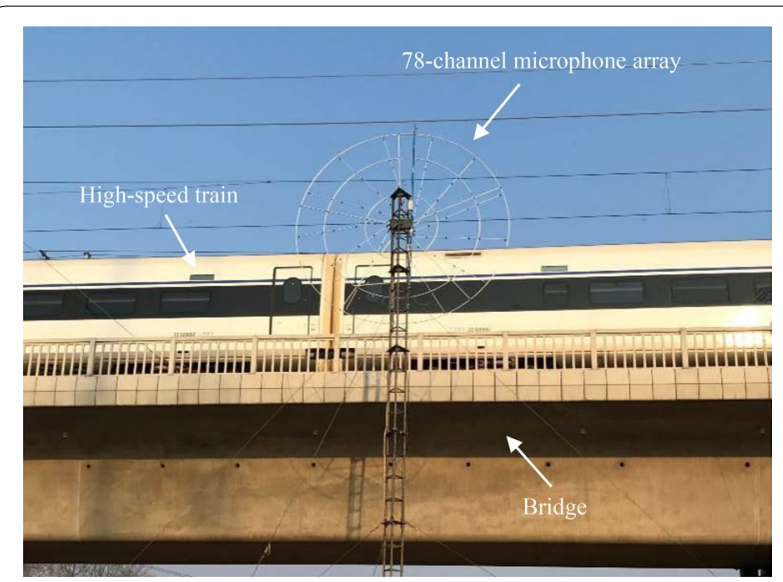

Figure 1 Measurement photograph of the exterior noise source identification of a high-speed train 


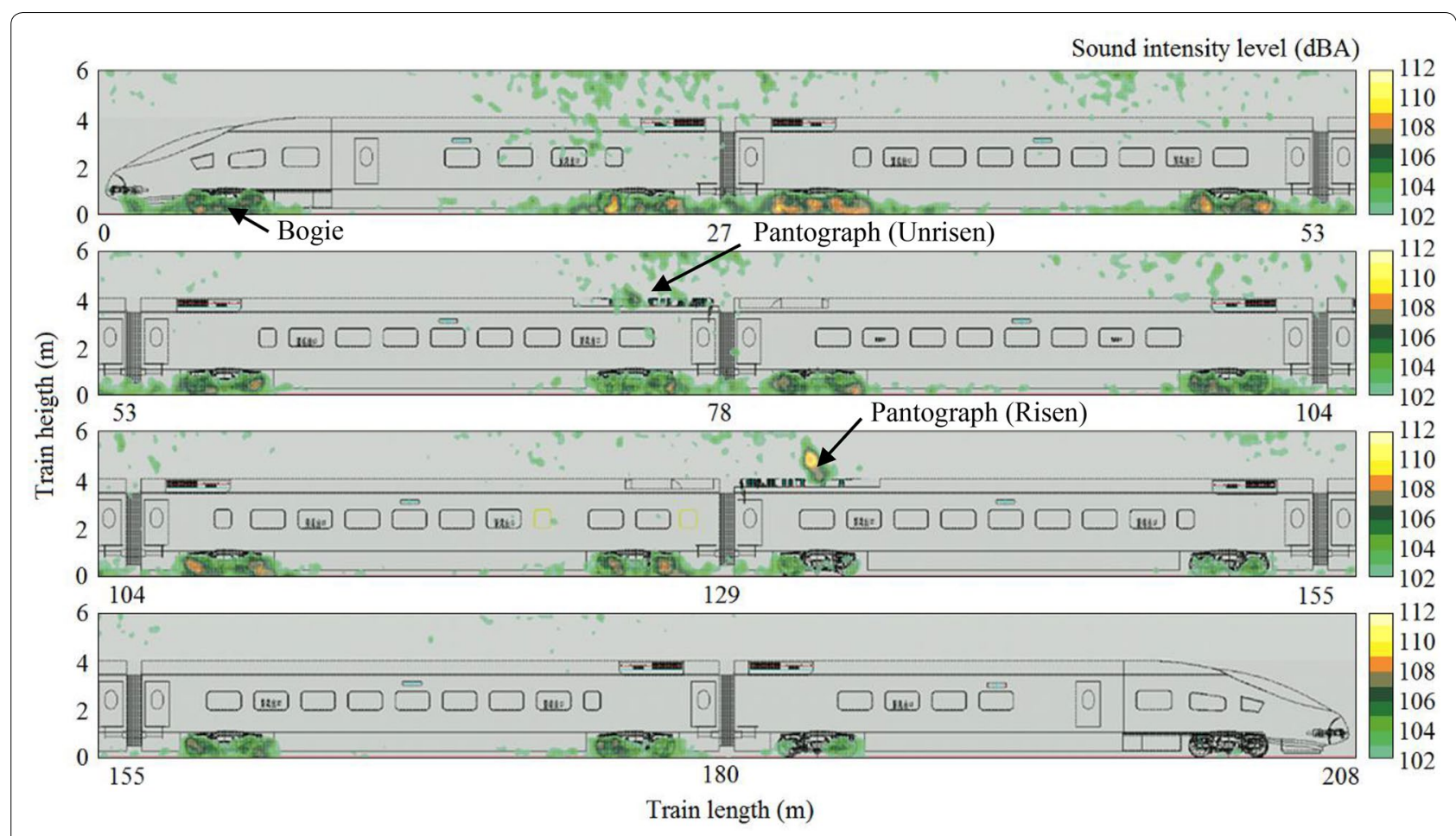

Figure 2 Exterior noise source distribution of the high-speed train running at $310 \mathrm{~km} / \mathrm{h}$ (frequency range: 500-5000 Hz)

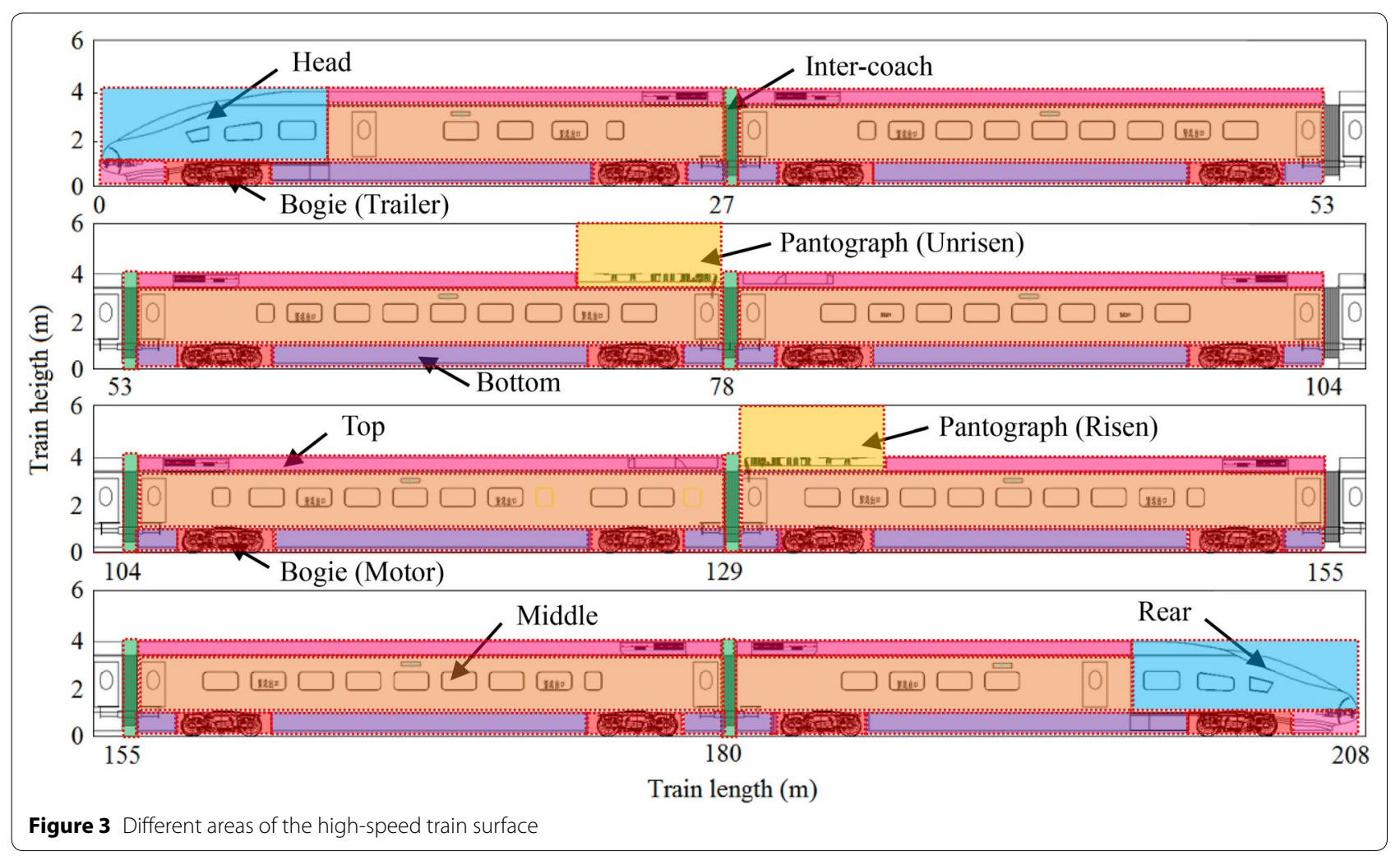


area, top area of the coach, middle area of the coach, and bottom area of the coach. The sound power is then obtained by integrating the sound intensity over each area, with each contribution calculated by using

$$
C_{s}=\frac{\int_{\Delta S} I(s) \mathrm{d} s}{\int_{S} I(s) \mathrm{d} s}
$$

where $I(s)$ is the sound intensity at a discrete point, $\Delta S$ is the area of each zone, and $S$ is the total area of all zones.

Figure 4 shows the contributions of different areas to the total sound power. As shown in Figure 4, when the high-speed train runs at $310 \mathrm{~km} / \mathrm{h}$, the contributions of the bogie area, bottom area of the coach, and middle area of the coach are relatively high, reaching $33.5 \%, 21.8 \%$, and $24.1 \%$, respectively. The contributions of the head and inter-coach areas are almost equal, $2.5 \%$ and $2.9 \%$, respectively. The rear area shows the lowest contribution, which is only $0.1 \%$. Although the source with one of the highest levels located at pantograph area, as indicated in Figure 2, its contribution is not very large. Because the high sound level only occupies small area, resulting in a low contribution.

The vertical distribution of the sound sources of the high-speed train expresses the intensity of the sound sources in the vertical direction and can be expressed through the single event sound level (SEL), given as

$$
\mathrm{SEL}=10 \times \log _{10}\left(\frac{\int_{L} I(l) \mathrm{d} l}{I_{\text {ref }}}\right),
$$

where $L$ is the length of the train, $I(l)$ is the sound intensity in the horizontal direction of the carbody, and $I_{\text {ref }}$ is the reference sound intensity, equal to $1 \mathrm{pW} / \mathrm{m}^{2}$. The area of the exterior noise source distribution of the highspeed train (as indicated in Figure 3) was $208 \mathrm{~m}$ in length

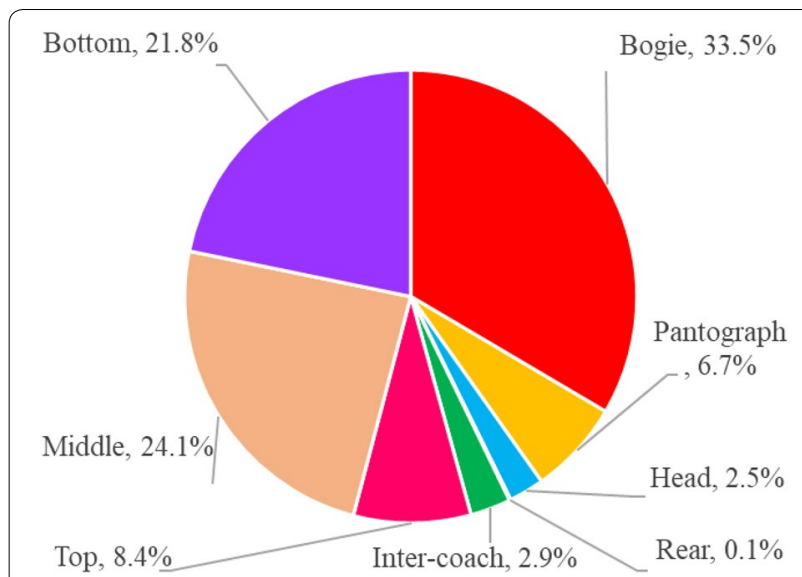

Figure 4 Contributions to the total sound power from different areas of the train and $6 \mathrm{~m}$ in height. The grid step was selected as $0.1 \mathrm{~m}$. Hence, Eq. (2) is the sound intensity integration in the horizontal direction of the beamforming acoustic map.

Figure 5 shows the vertical distribution of the exterior noise sources of the high-speed train running at $310 \mathrm{~km} / \mathrm{h}$. From Figure 5, when the high-speed train is running at $310 \mathrm{~km} / \mathrm{h}$, the maximum sound intensity level in the vertical distribution is $126.3 \mathrm{dBA}$, corresponding to a height of $0.2 \mathrm{~m}$ above the railhead. The minimum sound intensity level of $115.0 \mathrm{dBA}$ corresponds to a height of $1.4 \mathrm{~m}$. Their height difference is $1.2 \mathrm{~m}$, while their sound intensity level difference is $11.3 \mathrm{dBA}$. For heights from $1.4 \mathrm{~m}$ to $5.8 \mathrm{~m}$, the sound intensity level increases with height. During the pass-by time, the sound intensity level in the vertical distribution is maximised in the bogie area, followed by the bottom area of the coach, the pantograph area, the top area of the coach, and the middle area of the coach. This order is somewhat different from the chart of relative contributions of different areas to the total sound power shown in Figure 4. The reason is mainly the way in which we divide the coach area. For example, in Figure 5, the pantograph area covers the entire length of the train; however, in Figure 4, the pantograph area covers only a part of the train area.

\subsection{Distribution of Interior Sound Sources}

Figure 6 shows the setup used for the measurement of the interior noise sources of the high-speed train running at $310 \mathrm{~km} / \mathrm{h}$, performed using a spherical microphone array with 50 channels and 12 cameras (B\&K WA1565W004). The diameter of the array is $19.5 \mathrm{~cm}$, which is acoustically much smaller than the dimensions of the coach. The end of the first coach was chosen as a research object, and the

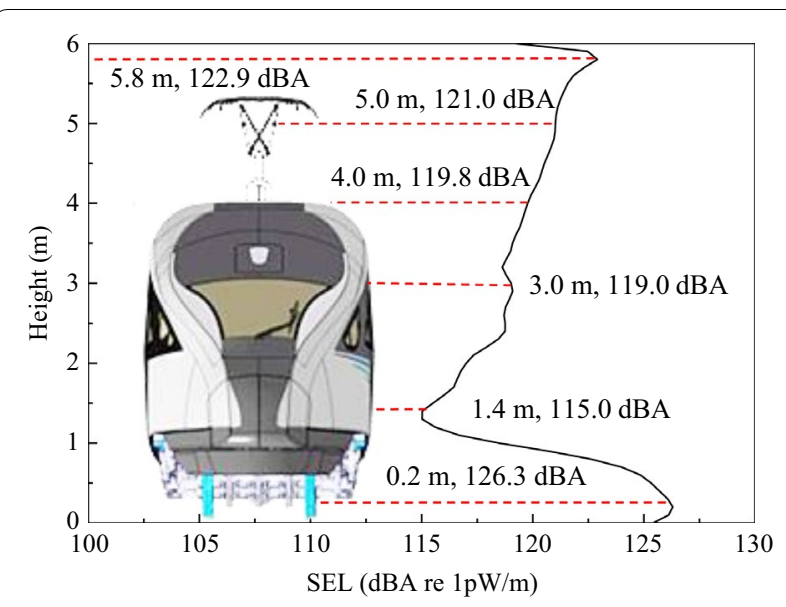

Figure 5 Vertical distribution of the exterior noise sources of the high-speed train running at $310 \mathrm{~km} / \mathrm{h}$ (frequency range: 500 $5000 \mathrm{~Hz})$ 


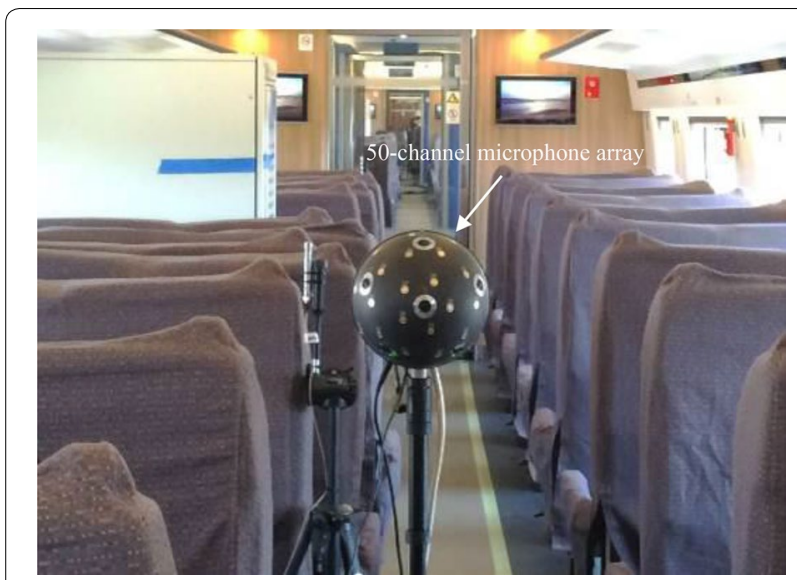

Figure 6 Measurement photograph of the interior noise source identification

array was positioned with its centre at a height of $1.2 \mathrm{~m}$ above the interior floor. The interior noise and the exterior noise were measured on the same train and at the same time.

The software B\&K NSI array acoustics post-processing was used for the interior noise source identification analysis, and the method is called spherical harmonics beamforming $[25,26]$. Figure 7 illustrates the distribution of the interior noise sources at the end of the first coach.

From Figure 7, the main interior sources at the end of the first coach are located in the sidewall and the roof. However, as indicated in Figure 2, the main exterior noise source of the first coach is the bogie area noise, which is located under the floor. Therefore, the mechanism of the noise transfer from the exterior to the interior of the train needs to be understood. Moreover, even though the exterior and interior sources are located in the same area, it is important to identify how much noise is transferred through the airborne path and how much through the structure-borne path, because the noise control measures are directly influenced by these factors.

The interior surface at the end of the coach is divided into six areas as shown in Figure 8, which are the roof, left sidewall, right sidewall, floor, front, and rear.

Figure 9 shows the contributions to the total sound power from the different interior areas. It can be seen from Figure 9 that, when the high-speed train runs at $310 \mathrm{~km} / \mathrm{h}$, the roof area shows the highest contribution of $25.0 \%$. This is related to the air conditioner noise outside the roof. The contributions of the floor, left sidewall, and right sidewall areas are almost equal and measure $18.4 \%$, $16.2 \%$, and $17.0 \%$, respectively. The front area is associated with the lowest contribution of $8.6 \%$, whereas the contribution of the rear area is $14.8 \%$. More noise comes from the rear than from the front because the measured point is located at the end of the coach.

Therefore, the distribution of sound sources and the contributions to the total sound power from different areas of the exterior and interior are quite different. The interior noise characteristics are not only affected by the exterior sound sources but also related to the sound transfer paths. Before studying the sound transfer path from the exterior to the interior, it is necessary to further analyse the relationship between the exterior and interior noises.

\subsection{Relationships between the Exterior Noise and the Interior Noise}

Figure 10 shows the dependences of the interior noise, the bogie area noise, and the major exterior sound sources of different areas on the train speed. Because of the lack

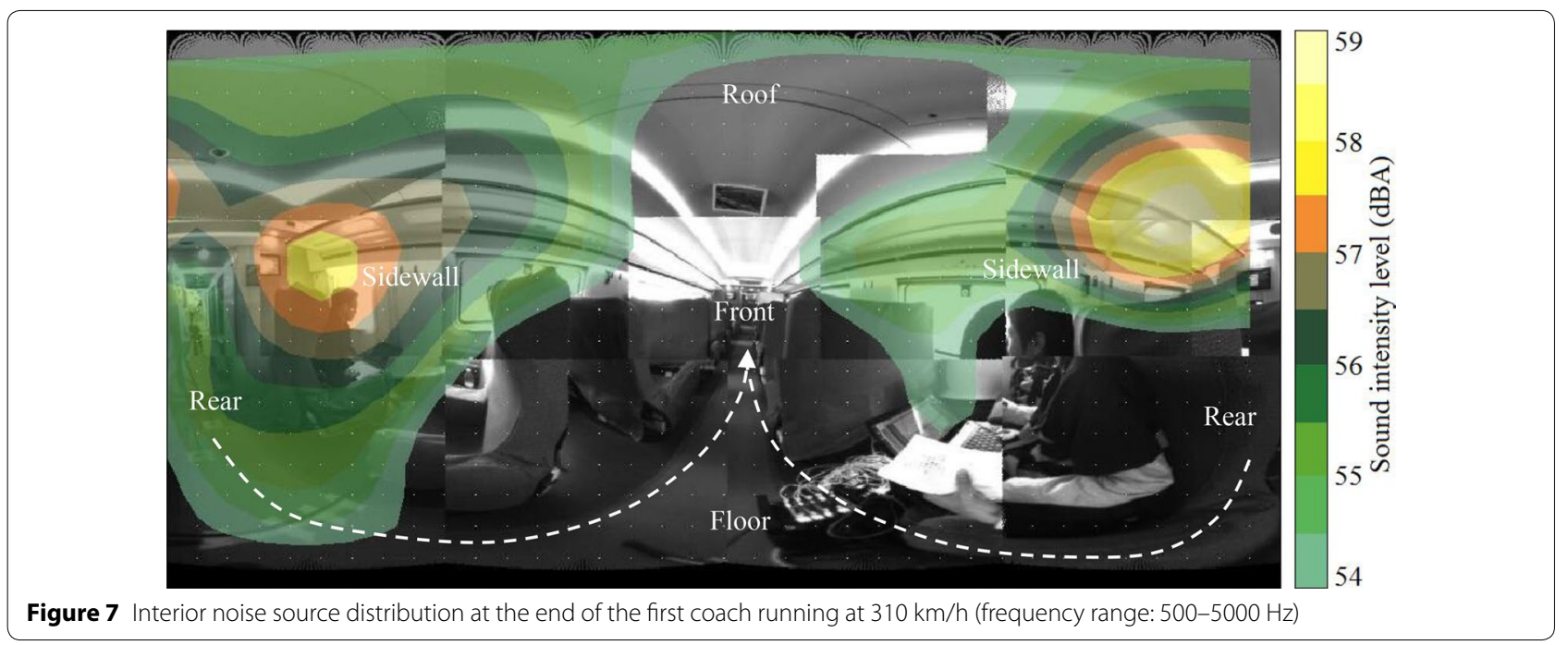




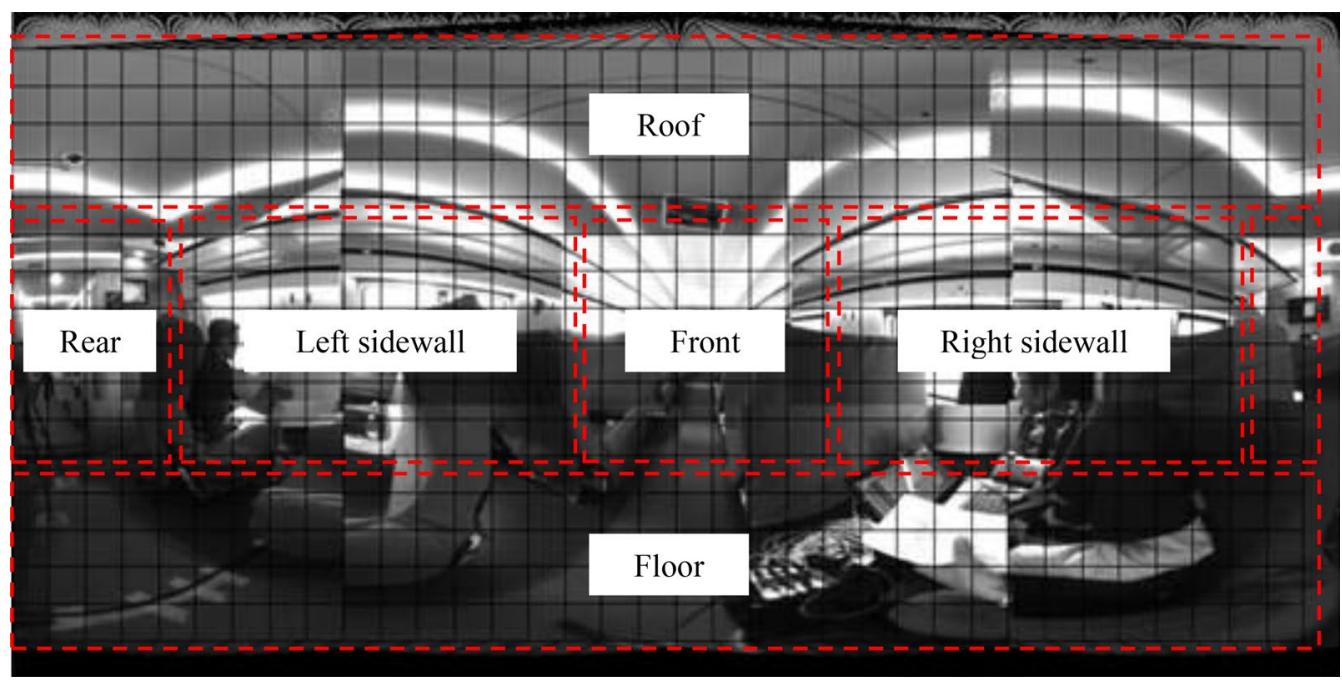

Figure 8 Different areas at the end of the first coach

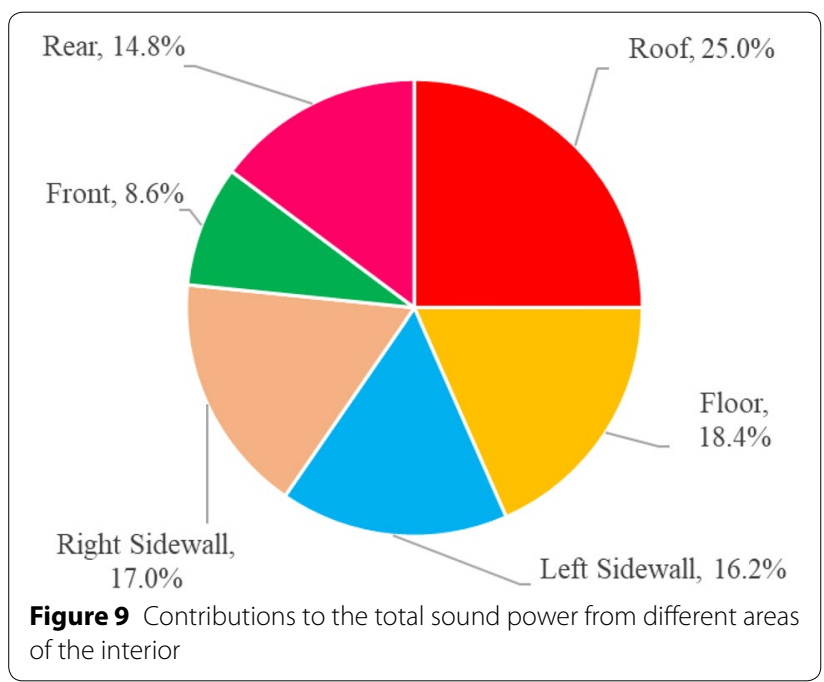

of measurement results on the interior noise sources at different speeds, we do not present those data. The interior noise is measured by a microphone positioned $1.2 \mathrm{~m}$ above the interior floor at the end of the first coach, and the bogie area noise is measured by a microphone fixed in the middle of the second bogie of the first coach. For both interior noise and bogie area noise, we use sound pressure level, whereas for all the exterior sound sources in different areas, we use sound power level.

As shown in Figure 10, when the train speeds are between $200 \mathrm{~km} / \mathrm{h}$ and $350 \mathrm{~km} / \mathrm{h}$, the interior noise, the bogie area noise, and the major exterior sound sources in different areas all increase with the train speed, with the dependence expressed by the linear regression law as

$$
L(v)=a \times \log _{10}\left(v / v_{0}\right)+L\left(v_{0}\right),
$$

where $a$ is a coefficient, $v$ is the train speed, $L$ is either the sound pressure level or sound power level, and $v_{0}$ is the reference speed, which is $200 \mathrm{~km} / \mathrm{h}$. Table 1 shows the fitting results, where $R^{2}$ is the corresponding correlation coefficient. The bigger $a$ is, the faster the noise increases with the train speed.

It can be seen from Table 1 that the interior noise and bogie area noise both increase with the train speed at similar rates. This indicates that the bogie area noise (includes wheel/rail rolling noise and aerodynamic noise) contributes significantly to the interior noise. However, from the measurement results for the exterior sound sources, the rates corresponding to the bogie area sound source and bottom of the coach sound source are lower than that of the interior noise. This is related to the details of the noise source measurement, with the results accounting only for the side surface of the coach. However, the bogie area noise directly transfers through the floor from the bottom of the train to the interior. In addition, the increased rates corresponding to the top and middle of the coach are similar to that of the interior noise, which indicates that the outside sources provide important contributions to the interior noise.

\section{Sound Transfer Paths from the Exterior to the Interior}

\subsection{Principle of the Sound Transfer Paths}

The exterior sound sources can contribute to the interior noise through airborne and structure-borne transfer paths. Figure 11 shows sound transfer paths under different conditions. 


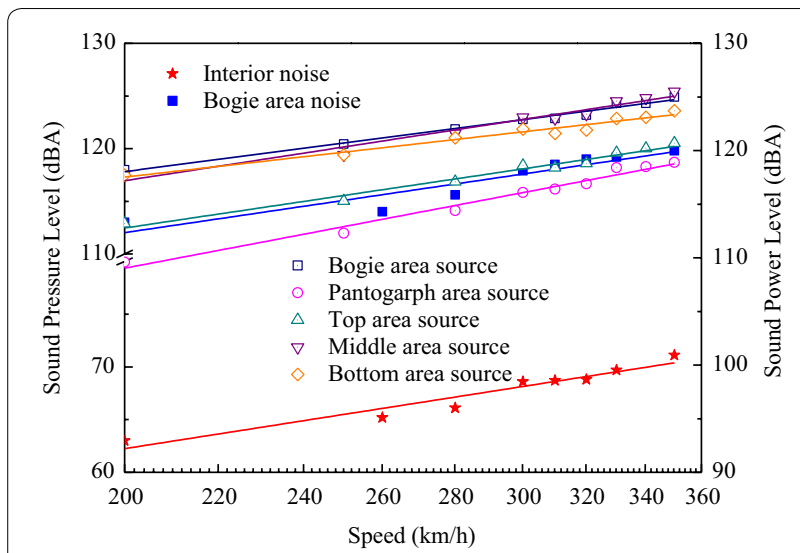

Figure 10 Relationships between the exterior noise and the interior noise at different speeds

Because the main interior noise sources at the end of the first coach are located at the sidewall and roof, we take the sidewall as an example. When the train runs at a constant speed, as shown in Figure 11(a), the sound transferred through the sidewall includes both airborne sound and structure-borne sound. For high-speed trains, the coach is usually well sealed with negligible sound leakage; therefore, the airborne sound is transmitted from the exterior air environment to the coach (to excite structural vibration) and then to the interior air environment, whereas the structure-borne sound is only transmitted from the coach structural vibration to the interior air environment.

When the train is stationary, and all equipment are shut down, there is no excitation. In that condition, if an airborne source is placed outside the train, as shown in Figure 11(b), there will be only airborne sound transferred through the sidewall.

In addition, the airborne sound transfer path transmits the noise from the exterior sources facing the path at the sidewall, such as the bogie area noise and aerodynamic noise, whereas the structure-borne sound transfer path transmits the noise from the exterior vibration sources and related structural vibration propagation, such as the wheel and bogie frame vibrations.

Table 1 Fitting results for the exterior and interior noises at different speeds

\begin{tabular}{|c|c|c|c|c|c|c|c|}
\hline & Interior noise & Bogie area noise & $\begin{array}{l}\text { Bogie area } \\
\text { source }\end{array}$ & $\begin{array}{l}\text { Pantograph area } \\
\text { source }\end{array}$ & Top area source & $\begin{array}{l}\text { Middle area } \\
\text { source }\end{array}$ & $\begin{array}{l}\text { Bottom } \\
\text { area } \\
\text { source }\end{array}$ \\
\hline$a$ & 33.5 & 31.6 & 27.6 & 40.0 & 31.3 & 32.4 & 24.0 \\
\hline$L\left(v_{0}\right)$ & 63.0 & 113.0 & 118.2 & 109.6 & 113.2 & 117.8 & 117.7 \\
\hline$R^{2}$ & 0.92 & 0.87 & 0.99 & 0.98 & 0.98 & 0.96 & 0.96 \\
\hline
\end{tabular}

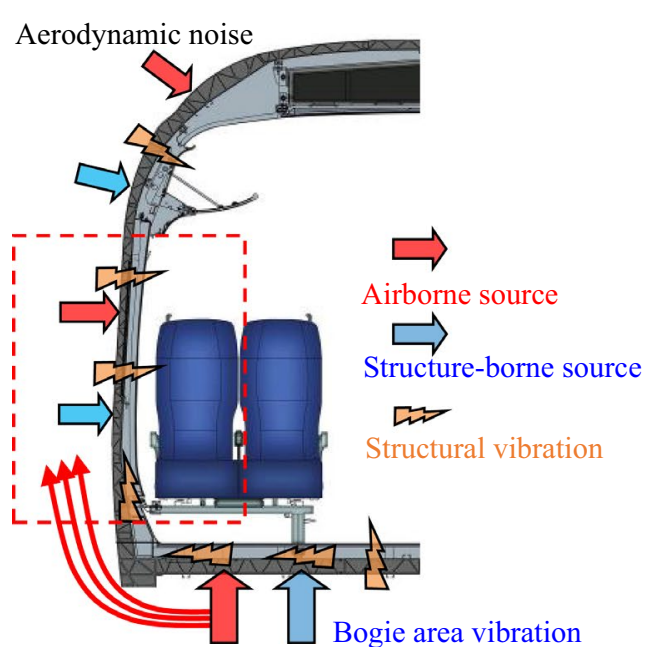

Bogie area noise

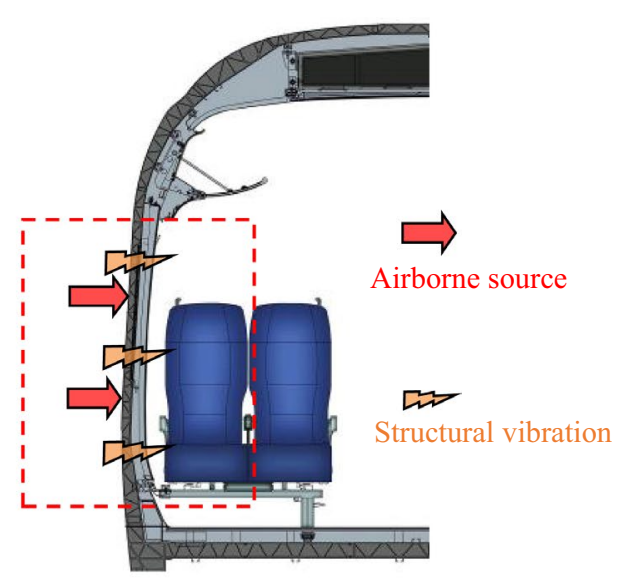

(a) Running at a constant speed

(b) Stationary

Figure 11 Sound transfer paths through the sidewall under different conditions 


\subsection{Method of the Transfer Contribution Analysis}

Based on the description of the sound transfer path from the exterior to the interior, a method for analysing the contribution of airborne sound can be devised as shown in Figure 12.

The defined airborne sound transmission loss (or sound insulation) is $T_{\text {air }}$ From Figure 11(b), for a sidewall area with superficial area $S$, if the incident sound power from the exterior is $W_{1}$, and the sound power transmitted to the interior is $W_{2}, T_{\text {air }}$ is given by

$$
T_{\text {air }}=10 \times \log _{10}\left(W_{1} / W_{2}\right) \text {. }
$$

The defined structure-borne radiation sound power is $W_{\text {str. }}$ From Figure 11(a), the total sound power radiated by the sidewall is a sum of the airborne sound power and the structure-borne sound power. If the measured incident sound power is denoted by $W_{1}^{\prime}$, the transmission coefficient of the sidewall is $\tau$, and the measured total sound power radiated by the sidewall is $W_{2}^{\prime}$, then

$$
W_{2}^{\prime}=\tau W_{1}^{\prime}+W_{\text {str }},
$$

where

$$
\tau=10^{-0.1 T_{\text {air }} .}
$$

Therefore, from the measured airborne sound transmission loss $T_{\text {air }}$ when the train is stationary and the measured incident sound power $W_{1}^{\prime}$ and total sound power radiated by the sidewall $W_{2}^{\prime}$ when the train runs at a constant speed, the contributions of the airborne and structure-borne sound can be calculated as

$$
\left\{\begin{array}{l}
C_{\mathrm{air}}=\frac{\tau W_{1}^{\prime}}{W_{2}^{\prime}}=\frac{W_{1}^{\prime} W_{2}}{W_{2}^{\prime} W_{1}}, \\
C_{\mathrm{str}}=\frac{W_{\mathrm{str}}}{W_{2}^{\prime}}=1-C_{\mathrm{air}},
\end{array}\right.
$$

where $C_{\text {air }}$ and $C_{\text {str }}$ are the airborne and structure-borne sound contribution rates, respectively.

\section{A Case Study of Noise from the Sidewall Area of the High-Speed Train}

\subsection{Measurement and Analysis for the Stationary Condition}

\subsubsection{Measurement Configuration}

When the train is stationary, the airborne sound transmission loss is measured by the sound intensity method near both sides of the sidewall. The selected sidewall area is at the coach end above a bogie. Due to the numerous windows on the sidewall, the selected area includes both a window and a part of the wall, as shown in Figure 13. The sidewall is $4 \mathrm{~m}$ from the gangway, and during the test both the inner end door and the gangway door are closed. This way, we ensure that the noise coming from the coach end has little influence. The dimensions of the sidewall are $1200 \mathrm{~mm}$ by $1200 \mathrm{~mm}$, and those of the window are $750 \mathrm{~mm}$ by $790 \mathrm{~mm}$; thus, the window accounts for $41 \%$ of the total area.

By integrating the sound intensity over a certain area, the sound power contributed by that area can be obtained. Therefore, we divide the studied area into a grid for measuring the sound intensity near the two sides of the sidewall as shown in Figure 14. In general, increasing the number of nodes in the grid leads to more accurate results. However, due to the limitations on the acquisition time of the in-situ measurement, grid step is selected as $300 \mathrm{~mm}$. Then, there are 25 nodes on each side of the sidewall. The sound intensities are measured at each node.

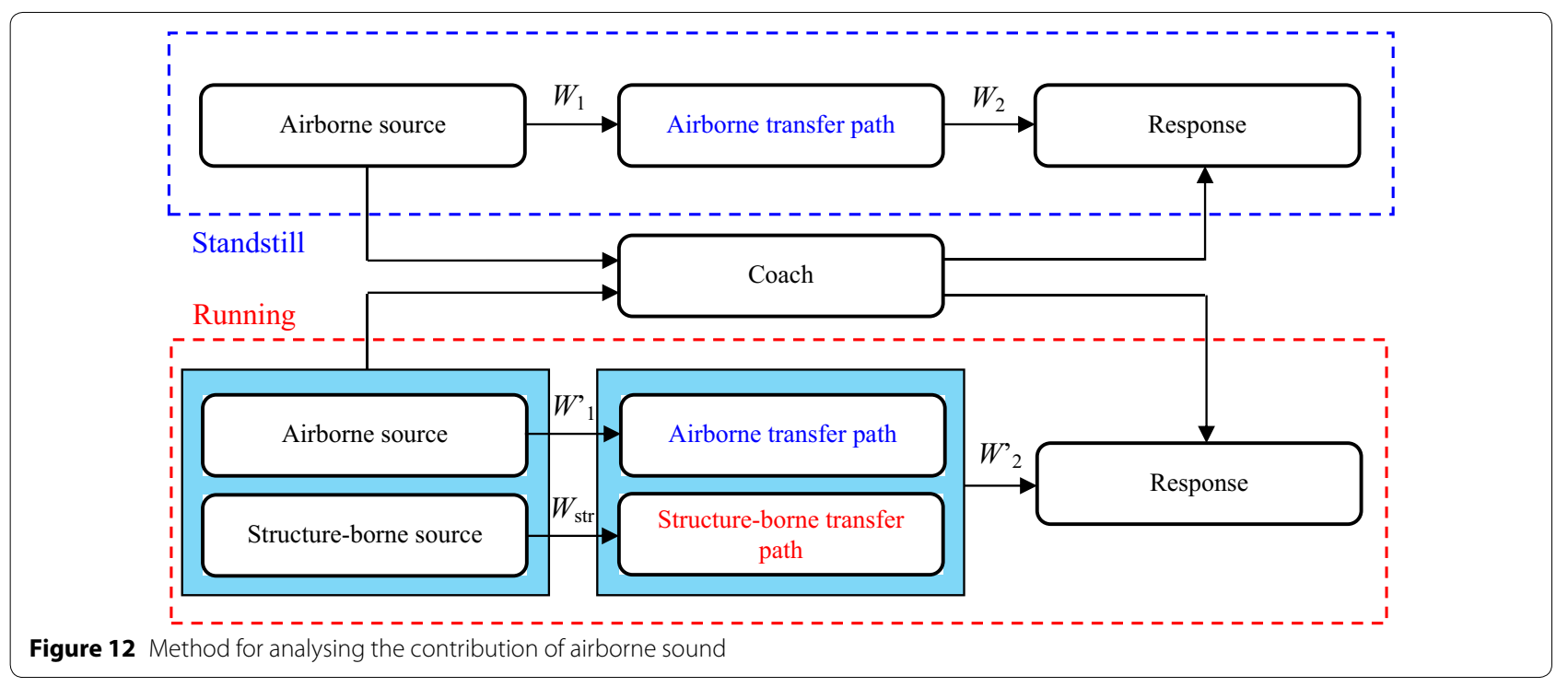




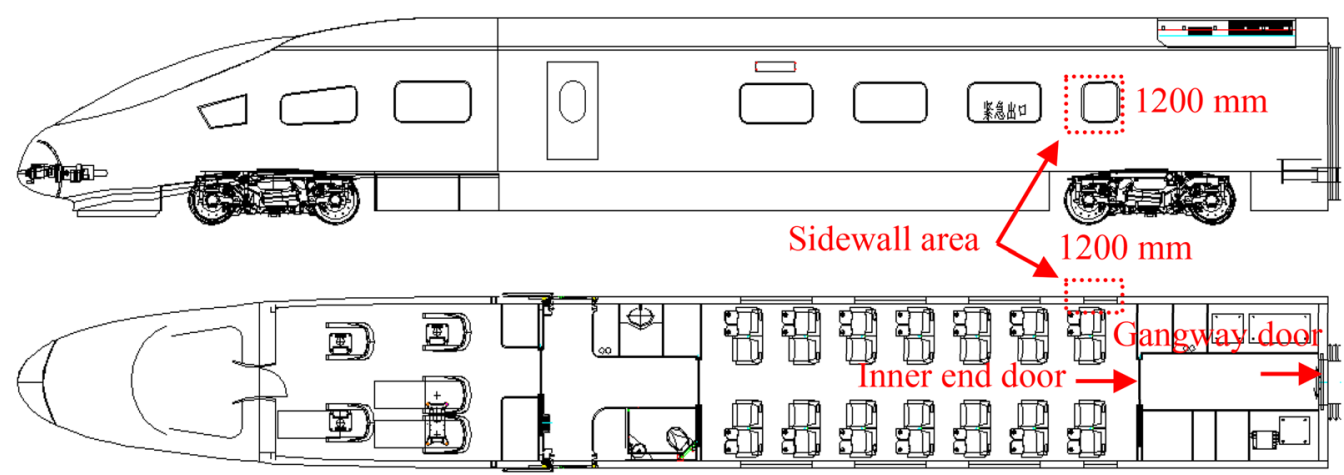

Figure 13 Test area of the sidewall of the high-speed train

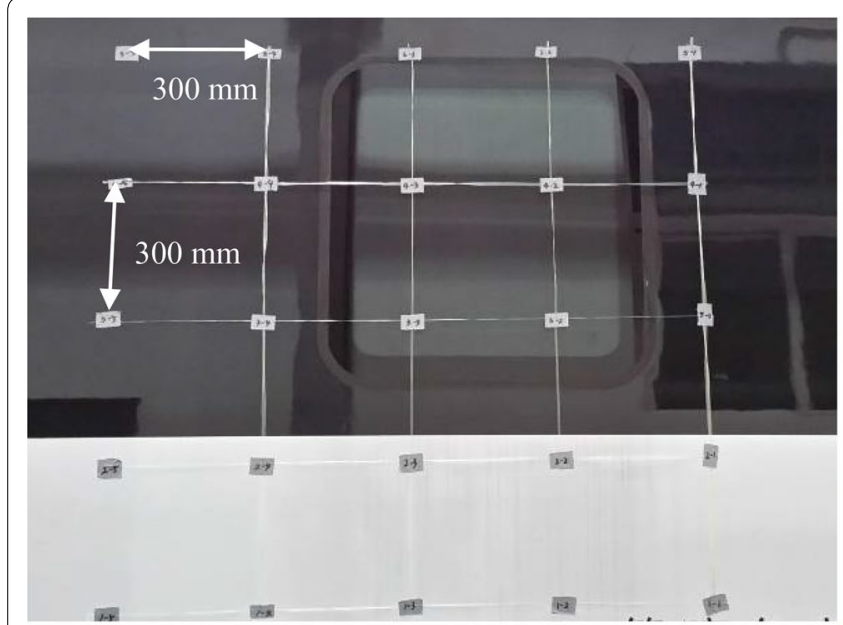

(a) Exterior

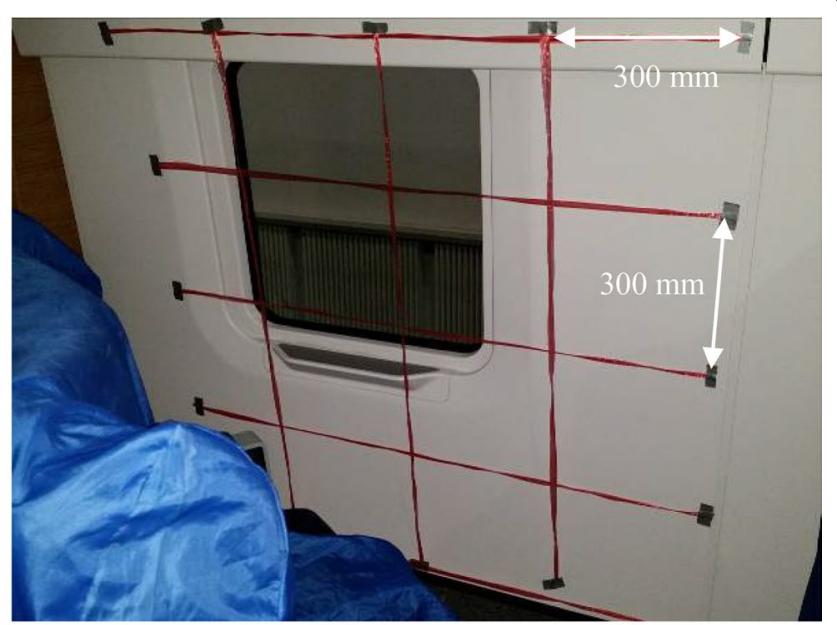

(b) Interior

Figure 14 Measurement points on the sidewall

Two B\&K Omni Power Sound Sources (B\&K 4292-L) were placed inside the coach in order to obtain sufficient sound power and produce a close-to-reverberant sound environment. The two sources are independent and nondirectional. White noise was used for excitation, with the upper frequency of $5000 \mathrm{~Hz}$. Meanwhile, two sound intensity probes (B\&K 3599) were used, one inside the coach and the other outside, to measure the sound intensities on the sidewall, as shown in Figure 15.

Before the measurement, the sound intensity probes were calibrated by the acoustic calibrator (B\&K 4297). First, the sources were allowed to operate for $30 \mathrm{~s}$ to stabilise the sound environment, and then the sound intensity was measured for $30 \mathrm{~s}$ at each point on the grid.

\subsubsection{Airborne Sound Transmission Loss Analysis}

Figure 16 shows the measurement results for the sound intensity from the interior sidewall when the train is stationary. The view direction is from the exterior to interior. In addition to the values measured at the 25 points on the grid, values at other positions generated by linear interpolation with a step of $0.01 \mathrm{~m}$ are also shown. Figure 17 shows the sound intensity results in the $1 / 3$ octave bands.

It can be seen from Figure 16 that the sound intensity distribution on the interior sidewall is not uniform. There are higher levels on the upper part and lower levels on the middle and bottom parts. Although the sound sources had already radiated for $30 \mathrm{~s}$ before the sound intensity was measured, the acoustic field was still very complex, resulting in the differences in sound intensities between different parts of the interior sidewall as large as $10 \mathrm{~dB}$. These differences are likely related to the seats installed in the coach. The height of the seats corresponds to the middle and bottom of the sidewall, and they have a shielding effect on sound propagation. 


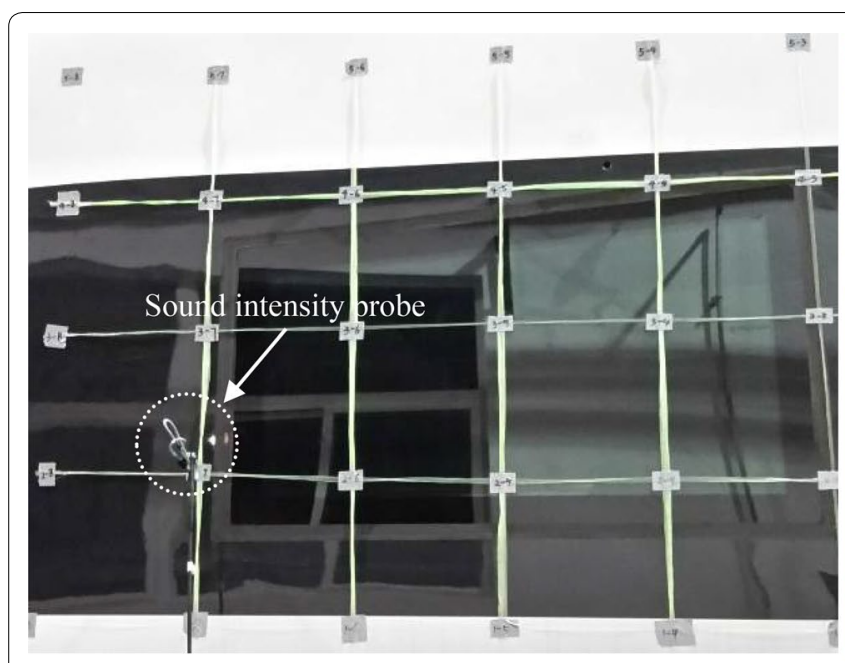

(a) Exterior

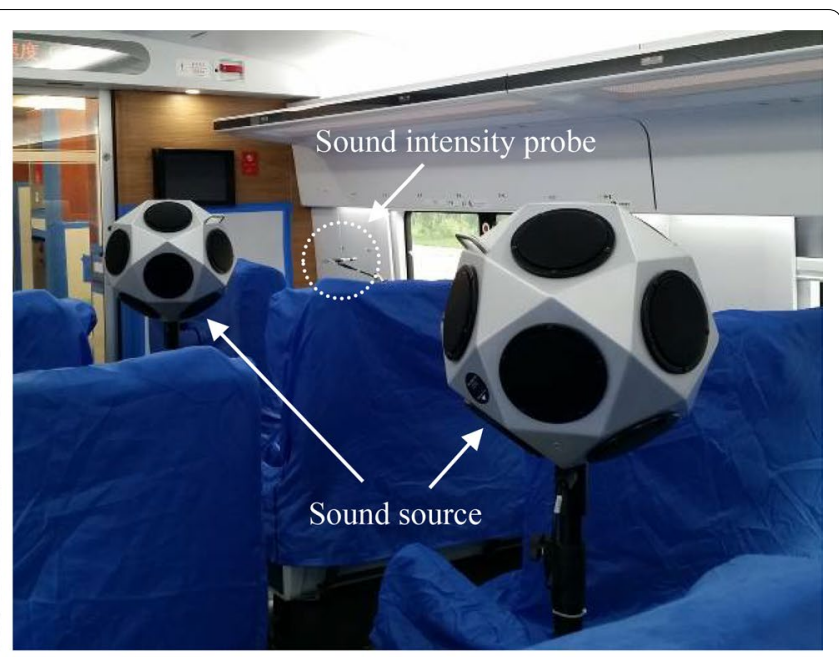

(b) Interior

Figure 15 Photographs of the airborne sound transmission loss measurement

From Figure 17, the average sound intensity spectrum from the 25 grid points shows a nearly straight horizontal line in the $1 / 3$ octave bands centred from $100 \mathrm{~Hz}$ to $3150 \mathrm{~Hz}$. However, the sound intensity levels in the $1 / 3$ octave bands centred from $400 \mathrm{~Hz}$ to $1600 \mathrm{~Hz}$ are slightly lower than those in other bands. This is related to the sound absorption by the interior structures, such as seats and interior trim.

Figure 18 shows the measurement results for the sound intensity of the exterior sidewall when the train is stationary. The view direction is again from the exterior to interior, and the overall spatial resolution is

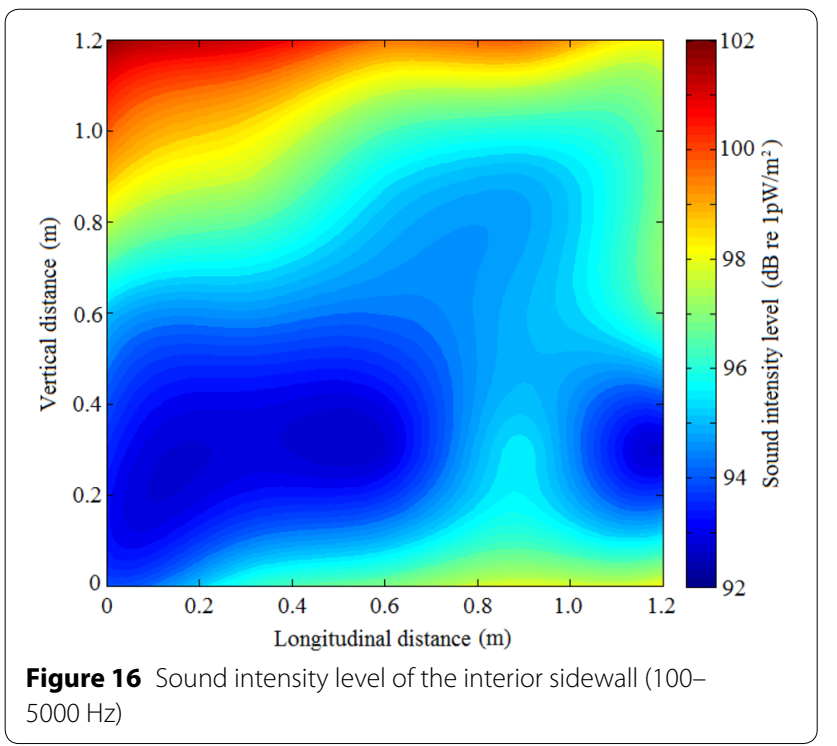

$0.01 \mathrm{~m}$. Figure 19 shows the sound intensity results in the $1 / 3$ octave bands.

It can be seen from Figure 18 that there are higher sound intensity levels on the left and right, and lower levels on the middle and bottom. The characteristics of the sound intensity distribution on the interior and exterior sidewalls are quite different. It is indicated that the noise from the airborne sound source transmitted through the sidewall not only defined by the characteristics of the source itself, but also affected by the structural characteristics and positions.

From Figure 19, the average sound intensity spectrum from the 25 points shows an obvious decreasing trend with increasing frequency, from $60 \mathrm{~dB}$ at $100 \mathrm{~Hz}$ to $20 \mathrm{~dB}$ at $4000 \mathrm{~Hz}$. It shows that the noise from the airborne sound source transmitted through the sidewall is frequency-dependent. In general, structures or materials have good acoustic performance with respect to parameters such as sound insulation and sound absorption at high frequencies.

The distribution characteristics of the sound intensities at both the interior and exterior sidewalls are related to the sound source excitation. Therefore, the airborne sound transmission loss must be considered to describe the noise transfer through the sidewall.

Since sound power is the integral of sound intensity over an area $S$, the airborne sound transmission loss can be expressed through the sound intensity as

$$
T_{\text {air }}=10 \times \log _{10}\left(W_{1} / W_{2}\right)=10 \times \log _{10}\left(I_{1} / I_{2}\right),
$$

where $I_{1}$ and $I_{2}$ indicate the incident and transmitted sound intensities for the area $S$, respectively. 




Figure 17 Sound intensity spectrum of the interior sidewall

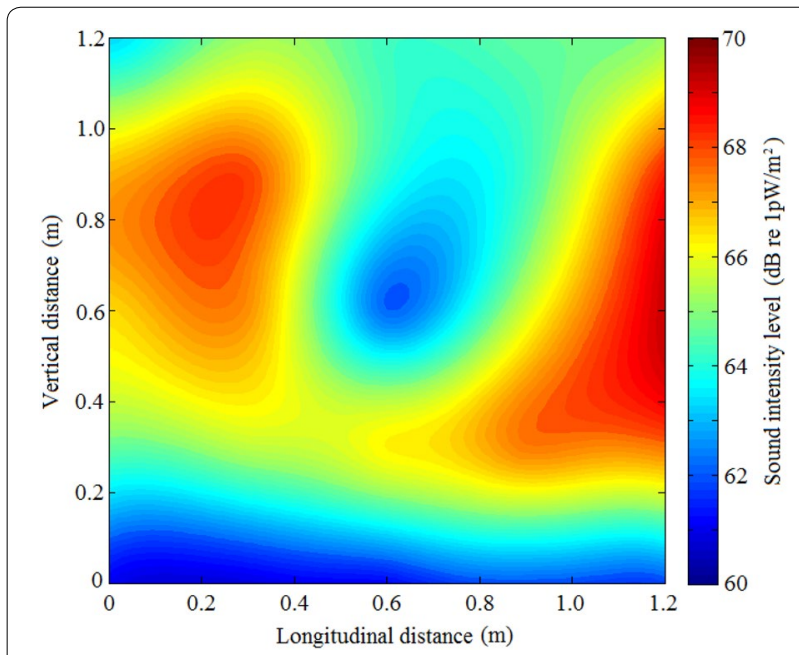

Figure 18 Sound intensity level of the exterior sidewall (100$5000 \mathrm{~Hz})$

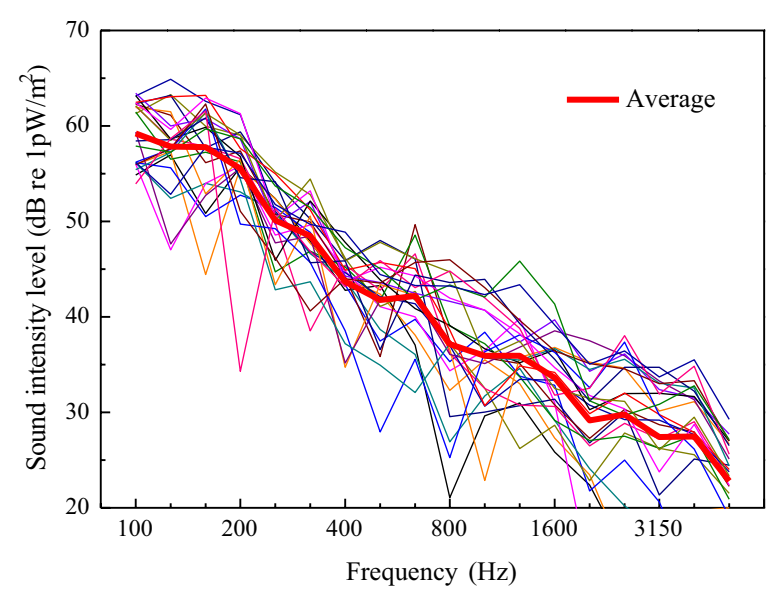

Figure 19 Sound intensity spectrum of the exterior sidewall
Figure 20 shows the airborne sound transmission loss for the sidewall. The view direction is from the exterior to the interior.

From Figure 20, there are lower airborne sound transmission loss levels on the lower middle, upper right, and bottom right, and higher levels on the upper left, middle right, lower left, and lower right. The maximum variation of the airborne sound transmission loss of the sidewall in the tested region is about $10 \mathrm{~dB}$. Lower losses mainly occur at the interface of the wall and window, especially around the lower-left and upper-right corners. It is related to the structural installation characteristics and the lack of acoustic materials at the interface.

Because the measurement points on two sides of the sidewall are matched to each other and uniformly arranged, the areas of the grid cells can be considered equal. Then, the average airborne sound transmission loss of the entire measured sidewall can be calculated from the mean sound intensities on the two sides of the sidewall expressed as

$$
T_{\text {air }}=10 \times \log _{10}\left(I_{1 \text { mean }} / I_{2 \text { mean }}\right),
$$

where $I_{1 \text { mean }}$ and $I_{2 \text { mean }}$ are the average sound intensities inside and outside of the sidewall, respectively.

Figure 21 shows the average airborne sound transmission loss of the sidewall as a function of frequency. The sound transmission loss increases with frequency, and its $R_{\mathrm{w}}$ (weighted sound reduction index) value is obtained as 42.4 dB. However, there are also some valleys in the $1 / 3$ octave bands centred at $160 \mathrm{~Hz}$ and $630 \mathrm{~Hz}$.

\subsection{Measurement and Analysis for the Running Condition 4.2.1 Measurement Configuration}

It is difficult to accurately measure the sound intensity outside the sidewall when the high-speed train is running. Therefore, the sound intensity results outside the sidewall are obtained with the microphone array, whereas those inside the sidewall are still measured by a sound intensity probe. The measured area of the sidewall for the running train is the same as that for the stationary train. However, due to limitations arising from the experimental conditions, the dimensions of the studied area of the sidewall in this measurement are $1000 \mathrm{~mm} \times 1000 \mathrm{~mm}$, whereas the number of the measurement points is still 25.

Figure 22 shows a photograph of the interior sound intensity measurement. The measurement begins when the train is running at a constant speed of $310 \mathrm{~km} / \mathrm{h}$. For each point, the sound intensity is acquired for $20 \mathrm{~s}$.

\subsubsection{Total Sound Power Radiation Analysis}

Figure 23 shows the measurement results for the sound intensity of the interior sidewall when the train is 


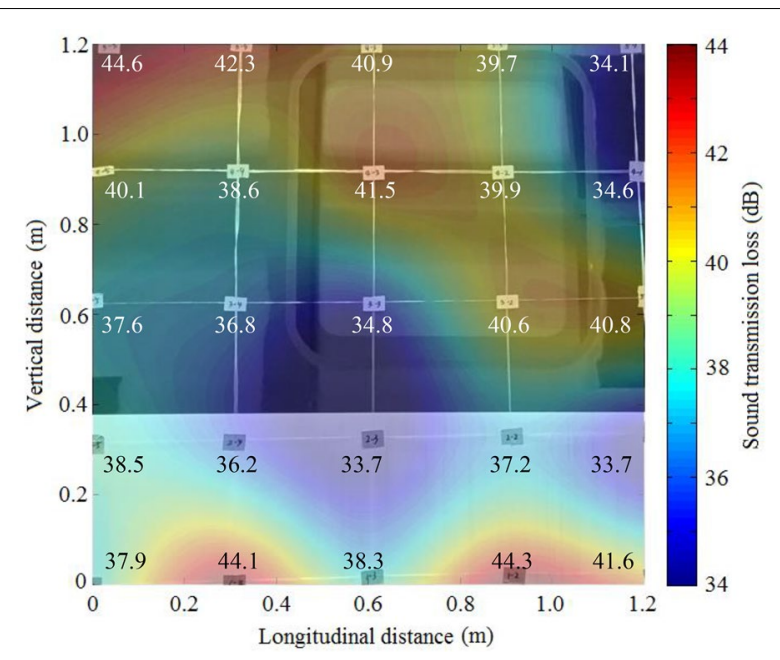

Figure 20 Airborne sound transmission loss of the sidewall



Figure 21 Average airborne sound transmission loss of the sidewall as a function of frequency

running at $310 \mathrm{~km} / \mathrm{h}$. The view direction is from the exterior to interior. In addition to the values measured at the 25 points of the grid, values at other positions generated by linear interpolation are also shown, making the overall spatial resolution $0.01 \mathrm{~m}$. Figure 24 shows the sound intensity results in the $1 / 3$ octave bands.

It can be seen from Figure 23 that there are high sound intensity levels inside the sidewall at the window and at the interface of the wall and window. Therefore, such areas radiate more noise from the exterior to the interior than other areas when the train is running at $310 \mathrm{~km} / \mathrm{h}$. The high noise level at the interface is related to the low airborne sound transmission loss, and the high noise level at the window is likely related to the dominant structural vibration, as the window is associated with high airborne sound transmission loss.

From Figure 24, it can be seen that the sound intensity levels decrease as the frequency increases. There are peaks in the $1 / 3$ octave bands centred at $125 \mathrm{~Hz}, 630 \mathrm{~Hz}$, $1000 \mathrm{~Hz}$, and $3150 \mathrm{~Hz}$. These peaks correspond to the valleys in the airborne sound transmission loss levels (for example, the dip at $630 \mathrm{~Hz}$ in Figure 21) and the peaks in the exterior noise and vibrations.

Figure 25 shows the measurement result for the exterior noise sources of the first two coaches when the train is running at $310 \mathrm{~km} / \mathrm{h}$. The sidewall area outside is selected to be the same as that inside, and the sound power, which is equal to the average sound intensity in this case (as the area is $1 \mathrm{~m}^{2}$ ), is obtained, as shown in Figure 26.

From Figure 26, the sound intensity levels are around $90 \mathrm{~dB}$ in the $1 / 3$ octave bands centred between $500 \mathrm{~Hz}$ and $3150 \mathrm{~Hz}$. However, they decrease for frequencies above $2500 \mathrm{~Hz}$. This is because the sidewall is located at the end of the coach; consequently, the levels are affected not only by the aerodynamic noise but also by the wheel/ rail rolling noise, with the rolling noise dominating in the $1 / 3$ octave bands centred between $500 \mathrm{~Hz}$ and $2000 \mathrm{~Hz}$ [27].

\subsection{Contribution of the Airborne Sound to the Interior Noise}

For the selected sidewall area, using the sound intensity method and Eq. (7), we can calculate the contribution of the airborne sound to the interior noise in the following way:

$$
\left\{\begin{array}{l}
C_{\text {air }}=\frac{I_{1 \text { mean }}^{\prime} I_{2 \text { mean }}}{I_{2 \text { maen }} I_{1 \text { mean }},} \\
C_{\text {str }}=1-C_{\text {air }},
\end{array}\right.
$$

where $I_{1 \text { mean }}$ and $I_{2 \text { mean }}$ are the average incident sound intensity and average radiated sound intensity, respectively, when the train is stationary. $I_{1 \text { mean }}^{\prime}$ and $I_{2 \text { mean }}^{\prime}$ are the average incident sound intensity and average radiated sound intensity, respectively, when the train is running at a constant speed. The results of the calculation according to Eq. (10) are shown in Figure 27.

From Figure 27, it can be seen that there is no particular trend for the contribution rate as a function of frequency in the $1 / 3$ octave bands centred from $500 \mathrm{~Hz}$ to $5000 \mathrm{~Hz}$. However, the structure-borne sound dominates for the majority of the bands, whereas the airborne sound only shows a dominant contribution in the bands centred at $2000 \mathrm{~Hz}, 2500 \mathrm{~Hz}, 4000 \mathrm{~Hz}$, and $5000 \mathrm{~Hz}$. It is important to note that this behaviour is related to the characteristics of the airborne sound transmission loss of the coach. That is, because the airborne sound transmission 


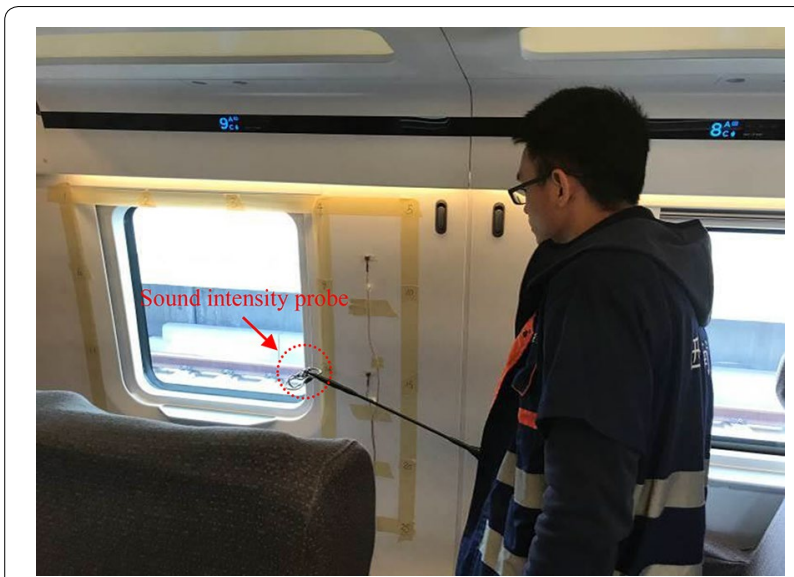

Figure 22 Photograph of the interior sound intensity measurement

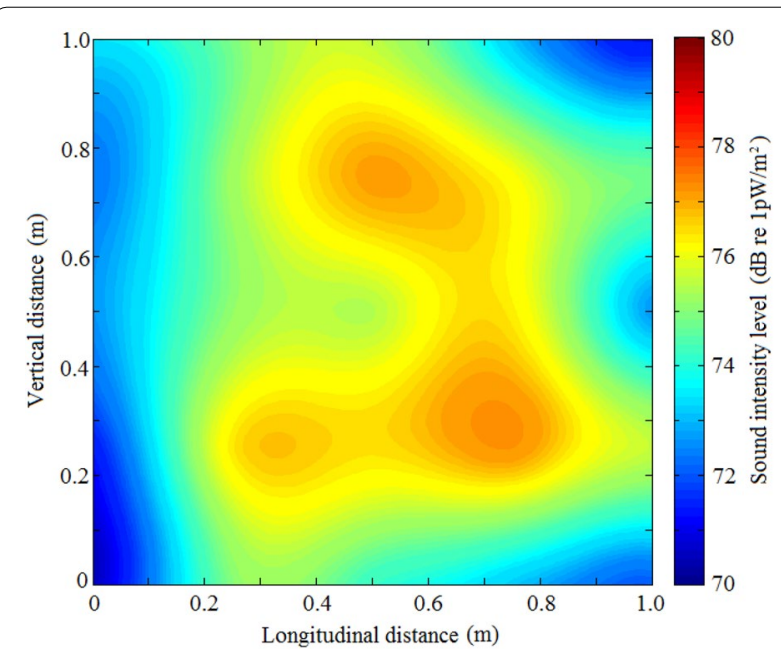

Figure 23 Sound intensity level of the interior sidewall (100-5000 $\mathrm{Hz})$

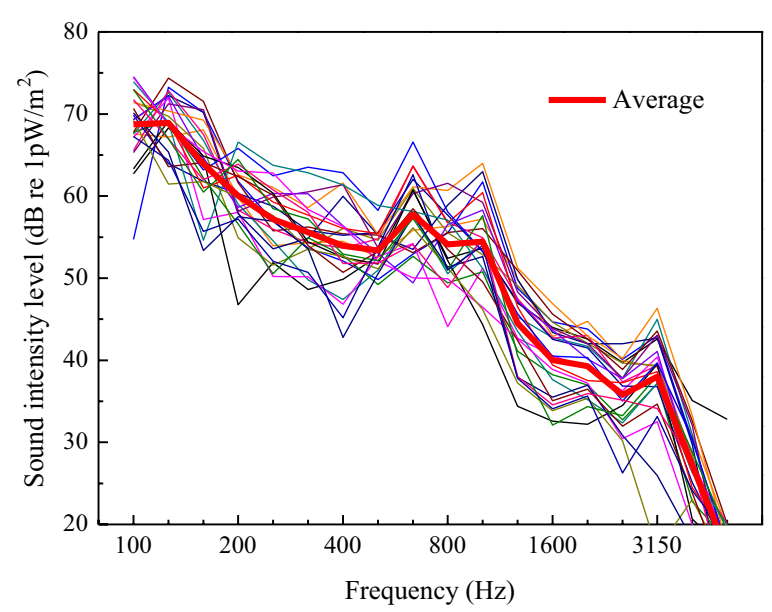

Figure 24 Sound intensity spectrum of the interior sidewall loss of the coach is sufficiently high to reduce the airborne sound, the contribution from the structure-borne sound becomes dominant.

\subsection{Discussion}

It is necessary to point out that the above method may be more suitable for the aerodynamic effect on the sidewall surface is not significant. This is because aerodynamic noise source near the sidewall has two components [28-30]: compressible acoustic pressure fluctuation and incompressible hydrodynamic pressure fluctuations, both exciting the wall to radiate noise inside the train. Due to the evanescent nature of the second component, the exterior noise estimated from microphone array measurement may only reflect the first component.

In response to this issue, we use a surface microphone fixed on the sidewall to measure the total pressure fluctuation. The contribution of airborne sound to the interior noise is reanalysed and compared with the previous one.

Figure 28 shows the measuring point of surface microphone on the sidewall outside. The surface microphone is installed at a height which corresponds to the centreline of the window, and approximately $0.25 \mathrm{~m}$ from the left edge of the window. In general, more surface microphones lead to more accurate results. However, in order not to change the turbulent flow on the sidewall surface, the number of microphones should be kept to be minimum.

Figure 29 shows the sound pressure level outside the sidewall when the high-speed train was running at $310 \mathrm{~km} / \mathrm{h}$. The sound pressure levels decrease as the frequencies increase, and the levels are almost $90-100 \mathrm{~dB}$ in the bands.

According to Eq. (10), the contribution of the airborne sound to the interior noise using sound pressure data can be expressed as

$$
\left\{\begin{array}{l}
C_{\text {air }}=\frac{p_{1 \text { mean }}^{\prime 2} p_{2 \text { mean }}^{2}}{p_{2 \text { mean }}^{\prime 2} p_{1 \text { mean }}^{2}} \\
C_{\text {str }}=1-C_{\text {air }},
\end{array}\right.
$$

where $p_{1 \text { mean }}$ and $p_{2 \text { mean }}$ are average incident sound pressure and average radiated sound pressure respectively when the train is stationary. $p_{1 \text { mean }}^{\prime}$ and $p_{2 \text { mean }}^{\prime}$ are average incident sound pressure and average radiated sound pressure respectively when the train is running at a constant speed.

Figure 30 shows a comparison in airborne sound contribution results between microphone array and surface microphone.

It can be seen from Figure 30 that there are some differences of the airborne sound contribution results in frequency bands, especially in the $1 / 3$ octave bands cantered at $1600 \mathrm{~Hz}, 2500 \mathrm{~Hz}$ and $4000 \mathrm{~Hz}$. It is 


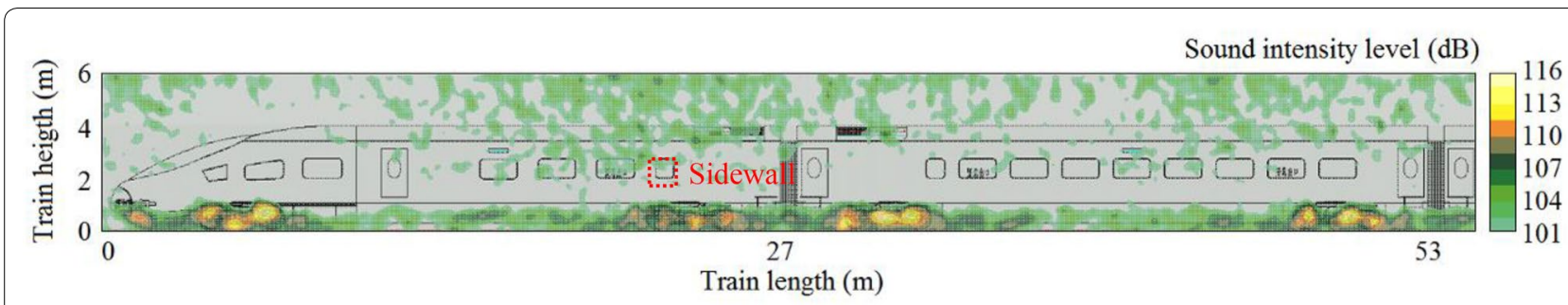

Figure 25 Measurement results for the exterior noise sources $(500-5000 \mathrm{~Hz}$, Linear weighted)

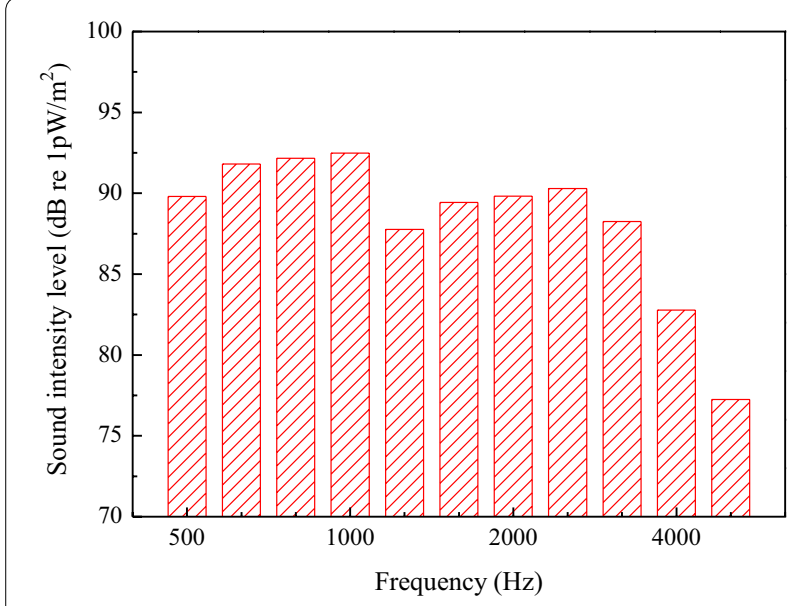

Figure 26 Average sound intensity spectrum of the exterior sidewall

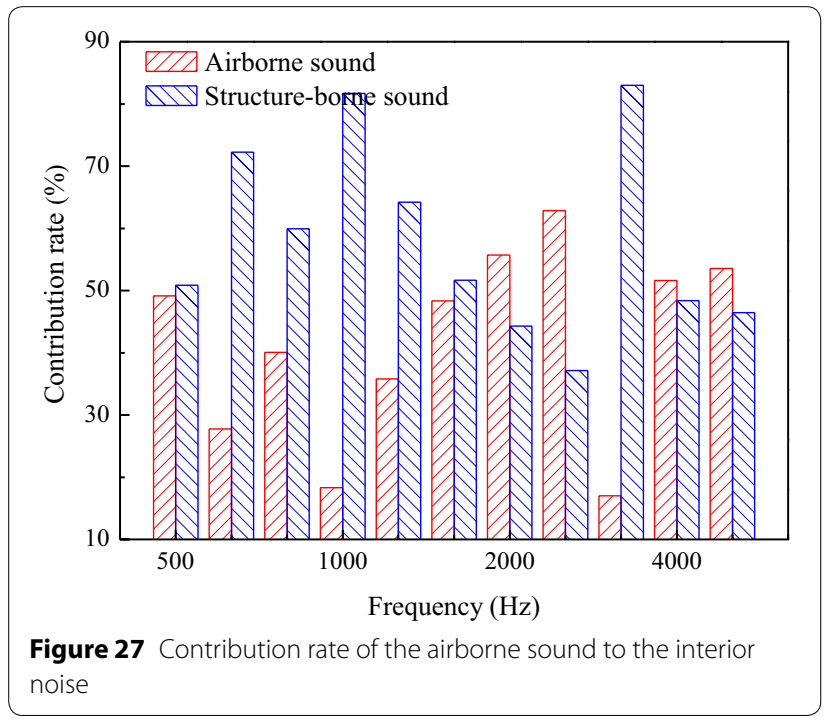

suggested to be caused by the incompressible hydrodynamic pressure fluctuations on the sidewall surface. However, because the two curves are close in most bands, the incompressible hydrodynamic pressure fluctuations on the sidewall may have little influence in this case. Nevertheless, it is still needed to do intensive study in the future

Furthermore, due to the experimental conditions, the contribution of the airborne sound to the interior noise is only investigated for the sidewall of a highspeed train. Even so, the method and obtained results are valuable for reference. At the same time, several issues remain and should be studied in the future. Here, we list some of them. First, in our measurement, when the train is stationary, the source is placed in the interior, whereas when the train is running at a constant speed, the source is placed outside the coach. Here, it is assumed that the noise transmissions from the interior to the exterior and in the opposite direction are equivalent, which is not necessarily true in reality. Second, the sound field inside the coach is neither a free sound field nor a reverberation sound field. Thus, the effect of acoustic reflection in the measurement needs further investigation. Last but not least, the sound sources outside the sidewall are very complex. They include not only the aerodynamic noise and vibration, but also the bogie area noise and vibration. The accuracy of the measurements needs to be further verified.

\section{Conclusions}

This study investigates both the exterior and interior sound source distributions of a high-speed train and presents a method for the contribution analysis of the airborne sound to the interior noise. The conclusions are as follows:

1. When the high-speed train runs at $310 \mathrm{~km} / \mathrm{h}$, the main exterior sound sources are located at the bogie and pantograph areas. Here, the bogie area, middle area of the coach, and bottom area of the coach provide dominant contributions to the total sound power.

2. When the high-speed train runs at $310 \mathrm{~km} / \mathrm{h}$, the main interior sound sources are located at the sidewall and roof. Here, the roof area provides the maxi- 


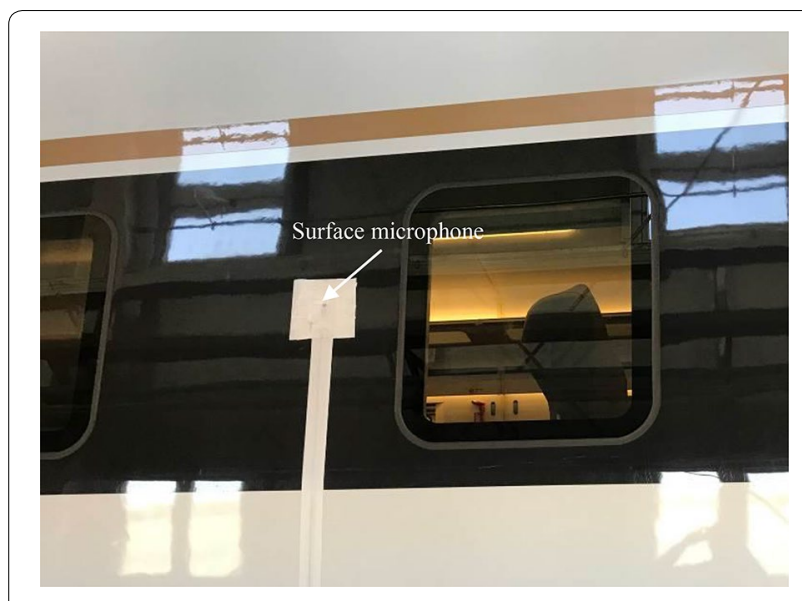

Figure 28 Photograph of the surface microphone installed on the sidewall outside
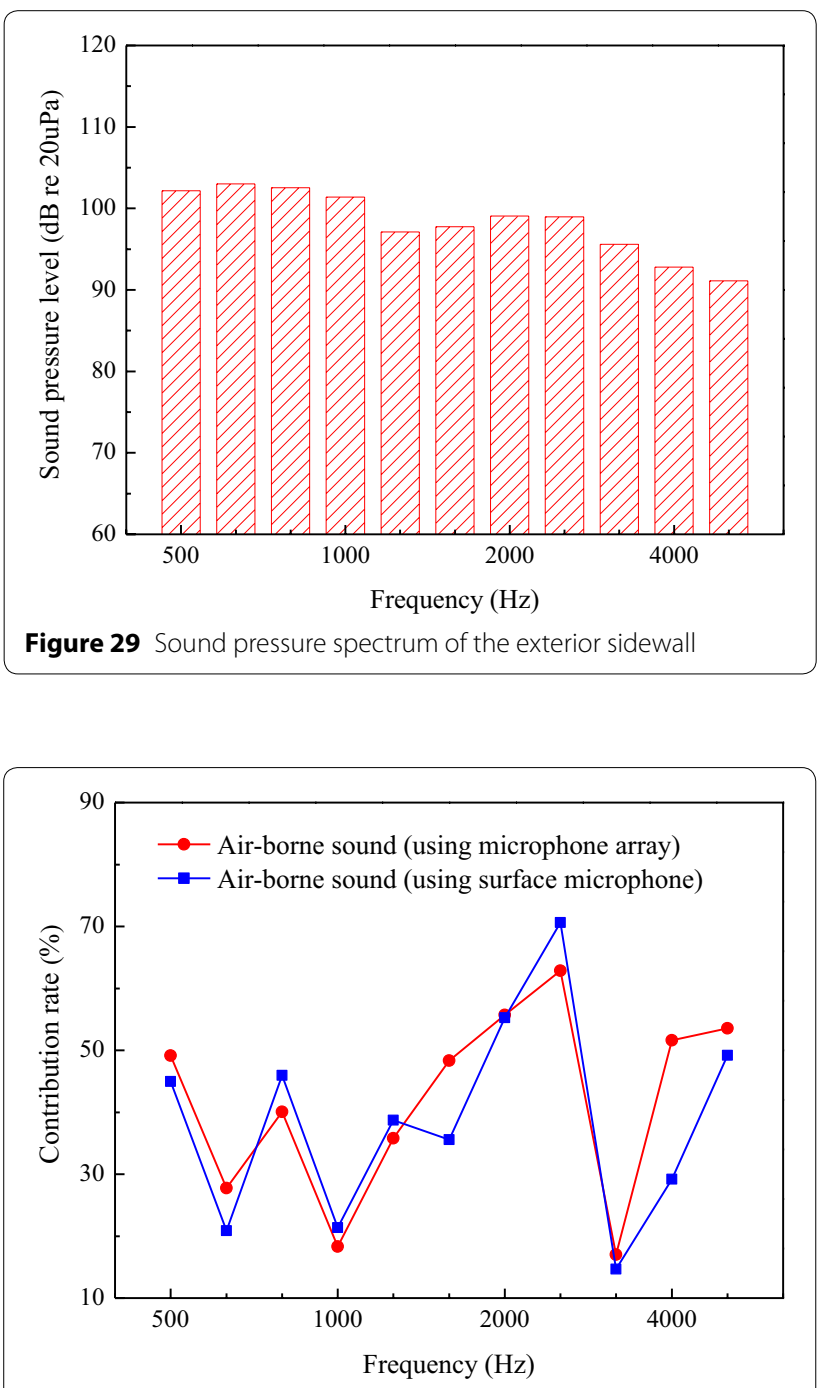

Figure 30 A comparison in airborne sound contribution results between using microphone array and using surface microphone mum contribution to the total sound power, followed by the floor, right sidewall, and left sidewall areas.

3. The interior noise, the bogie area noise and the sound source at the middle of the coach exhibit very similar rates of increase with increasing train speed. Therefore, the bogie area noise and the sound source at the middle of the coach contribute significantly to the interior noise.

4. For the selected sidewall area, the structure-borne sound dominates in the majority of the $1 / 3$ octave bands, whereas the airborne sound dominates only in the bands centred at $2000 \mathrm{~Hz}$ and $2500 \mathrm{~Hz}$. This behaviour is related to the characteristics of the airborne sound transmission loss of the coach.

\section{Authors' Contributions}

JZ put forward the method, analyzed the data and wrote the manuscript; XX and XS were in charge of the whole trial and reviewed the manuscript; ZL assisted with measurements and data analyses. All authors read and approved the final manuscript.

\section{Authors' Information}

Jie Zhang, born in 1987, is currently a postdoctor at State Key Laboratory of Polymer Materials Engineering / Polymer Research Institute, Sichuan University, China. He received his PhD degree from Southwest Jiaotong University, China, in 2018. His research interests include railway noise and vibration.

Xinbiao Xiao, born in 1978, is currently an associate professor at State Key Laboratory of Traction Power, Southwest Jiaotong University, China. He received his PhD degree from Southwest Jiaotong University, China, in 2013. His research interests include railway noise and vibration.

Xiaozhen Sheng, born in 1962, is currently a professor and a PhD candidate supervisor at State Key Laboratory of Traction Power, Southwest Jiaotong University, China. He received his PhD degree from University of Southampton, UK, in 2002. His research interests include railway noise and vibration.

Zhihui Li, born in 1988, is currently a research assistant at State Key Laboratory of Traction Power, Southwest Jiaotong University, China. He received his master degree from Southwest Jiaotong University, China, in 2016. His research interests include railway noise and vibration.

\section{Acknowledgements}

The authors sincerely thanks to Prof. Zhigang Chu (Chongqing University) and Associate Prof. Jianyue Zhu (Tongji University) for their critical discussion during the manuscript preparation, and thanks to Muxiao Li, Yumei Zhang, Moukai Liu, Rongchun Shi, Cai Tian, Yan Yang, et al. (Southwest Jiaotong University) for their assistances in the measurements and data processing.

\section{Competing Interests}

The authors declare no competing financial interests.

\section{Funding}

Supported by National Key R\&D Program of China (Grant No. 2016YFE0205200) and National Natural Science Foundation of China (Grant No. U1834201).

Received: 5 February 2018 Revised: 7 May 2019 Accepted: 2 July 2019 Published online: 17 July 2019

\section{References}

[1] A E J Hardy. Railway passengers and noise. Proceedings of the Institution of Mechanical Engineers Part F: Journal of Rail and Rapid Transit, 1999, 213(3): 173-180. 
[2] N I Ivanov, IS Boiko, A E Shashurin. The problem of high-speed railway noise prediction and reduction. Procedia Engineering, 2017, 189: 539-546.

[3] ZY Shen. Dynamic environment of high-speed train and its distinguished technology. Journal of the China Railway Society, 2006, 28(4): 1-5. (in Chinese)

[4] X S Jin. Key problems faced in high-speed train operation. Journal of Zhejiang University-Science A (Applied Physics \& Engineering), 2014, 15(12): 936-945.

[5] GW Yang, Y J Wei, G L Zhao, et al. Research progress on the mechanics of high speed rails. Advances in Mechanics, 2015, 45: 201507. (in Chinese)

[6] D J Thompson, P E Gautier. Review of research into wheel/rail rolling noise reduction. Proceedings of the Institution of Mechanical Engineers, Part F, Journal of Rail and Rapid Transit, 2006, 220(4): 385-408.

[7] N Frémion, N Vincent, M Jacob, et al. Aerodynamic noise radiated by the intercoach spacing and the bogie of a high-speed train. Journal of Sound and Vibration, 2000, 231(35): 577-593.

[8] P J Remington. Wheel/rail rolling noise I: theoretical analysis. Journal of the Acoustical Society of America, 1987, 81(6): 1805-1823.

[9] D J Thompson. Wheel-rail noise generation, part 1: introduction and interaction model. Journal of Sound and Vibration, 1993, 161(1993): 387-400.

[10] TXWu, D J Thompson. On the rolling noise generation due to wheel/ track parametric excitation. Journal of Sound and Vibration, 2006, 293(2006): 566-574

[11] X Sheng, T Zhong, Y Li. Vibration and sound radiation of slab high-speed railway tracks subject to a moving harmonic load. Journal of Sound and Vibration, 2017, 395(2017): 160-186.

[12] X Zhang, D J Thompson, $H$ Jeong, et al. The effects of ballast on the sound radiation from railway track. Journal of Sound and Vibration, 2017, 399(2017): 137-150.

[13] K Nagakura. Localization of aerodynamic noise sources of Shinkansen trains. Journal of Sound and Vibration, 2006, 293(2006): 547-556.

[14] E Latorre Iglesias, D J Thompson, M G Smith. Component-based model to predict aerodynamic noise from high-speed train pantographs. Journal of Sound and Vibration, 2017, 394(2017): 280-305.

[15] C Mellet, F Létourneaux, F Poisson, et al. High speed train noise emission: Latest investigation of the aerodynamic/rolling noise contribution. Journal of Sound and Vibration, 2006, 293(2006): 535-546.

[16] E Zea, L Manzari, G Squicciarini, et al. Wavenumber-domain separation of rail contribution to pass-by noise. Journal of Sound and Vibration, 2017, 409(2017): 24-42.
[17] R Ström. Operational transfer path analysis of components of a high-speed train bogie. Sweden: Chalmers University of Technology.

[18] R Fan, Z Su, G Meng. Application of sound intensity and partial coherence to identify interior noise sources on the high speed train. Mechanical Systems and Signal Processing, 2014, 46(2014): 481-493.

[19] J Zhang, X B Xiao, X Z Sheng, et al. SEA and contribution analysis for interior noise of a high speed train. Applied Acoustics, 2016, 112(2016): 158-170.

[20] J J Christensen, J Hald. Technical review beamforming. Denmark: Bruel \& Kjear, 2004

[21] J Hald. Estimation of partial area sound power data with beamforming INTER-NOISE and NOISE-CON Congress and Conference Proceedings, 2005.

[22] Z G Chu, Y Yang. Comparison of deconvolution methods for the visualization of acoustic sources based on cross-spectral imaging function beamforming. Mechanical Systems \& Signal Processing, 2014, 48(1-2): 404-422.

[23] J Zhang, X B Xiao, D W Wang, et al. Source contribution analysis for exterior noise of a high-speed train: experiments and simulations. Shock and Vibration, 2018: Article ID 5319460.

[24] B He, X B Xiao, Q Zhou, et al. Investigation into external noise of a highspeed train at different speeds. Journal of Zhejiang University-Science A (Applied Physics \& Engineering), 2014, 15(12): 1019-1033.

[25] B Rafaely. Plane-wave decomposition of the sound field on a sphere by spherical convolution. The Journal of the Acoustical Society of America, 2004, 116(4): 2149-2157.

[26] Z G Chu, Y Yang, Y S He. Deconvolution for three-dimensional acoustic source identification based on spherical harmonics beamforming. Journal of Sound and Vibration, 2015, 344(2015): 484-502.

[27] D J Thompson. Railway noise and vibration: Mechanisms, modelling and means of control. New York: Elsevier, 2009.

[28] C Peric, SWatkins, E Lindqvist. Wind turbulence effects on aerodynamic noise with relevance to road vehicle interior noise. Journal of Wind Engineering and Industrial Aerodynamics, 1997, 69-71(1997): 423-435.

[29] J Y Zhu, Z W Hu, D J Thompson. Flow simulation and aerodynamic noise prediction for a high-speed train wheelset. International Journal of Aeroacoustics, 2014, 13 (7\&8): 533-552.

[30] JY Zhu, ZW Hu. Flow between the train underbody and trackbed around the bogie area and its impact on ballast flight. Journal of Wind Engineering \& Industrial Aerodynamics, 2017, 166 (2017): 20-28.

\section{Submit your manuscript to a SpringerOpen ${ }^{\odot}$ journal and benefit from:}

- Convenient online submission

- Rigorous peer review

- Open access: articles freely available online

- High visibility within the field

Retaining the copyright to your article

Submit your next manuscript at $\boldsymbol{\nabla}$ springeropen.com 